CONGENITAL HEART DISEASE

\title{
Common arterial trunk in the fetus: characteristics, associations, and outcome in a multicentre series of 23 cases
}

\author{
P Volpe, D Paladini, M Marasini, A L Buonadonna, M G Russo, G Caruso, A Marzullo, M Vassallo, \\ P Martinelli, M Gentile
}

Heart 2003;89:1437-1441

See end of article for authors' affiliations

....................

Correspondence to: Dr Mattia Gentile, Department of Medical Genetics, IRCCS "Saverio de Bellis", via della Resistenza nc, 70013 Castellana Grotte, Bari, Italy; mattiagentile@ libero.it

Accepted 9 June 2003

\begin{abstract}
Objective: To assess the accuracy of prenatal diagnosis, the incidence of extracardiac and chromosomal anomalies, and the perinatal outcome in a population of fetuses with common arterial trunk (CAT). Design: Observational study of 23 fetuses from three referral centres with a confirmed diagnosis of CAT. All underwent fetal echocardiography, detailed anatomical scanning, and karyotyping. In 19 cases, FISH analysis was done to detect $22 q 11$ microdeletion. The following variables were evaluated: gestational age at diagnosis, anatomical variants of the CAT, presence of extracardiac and chromosomal anomalies, pregnancy, and fetal-neonatal outcome. Necropsy reports and postnatal files were available for confirmation of the prenatal diagnosis in all cases.

Results: The prenatal diagnosis proved correct in 23 of 24 cases, the last being pulmonary atresia with ventricular septal defect (PAVSD). A second cardiovascular anomaly was present in eight cases (34.8\%); extracardiac anomalies were found in 10 (43.4\%). FISH analysis showed 22q11 microdeletion in six of 19 cases (31.6\%). Outcomes were as follows: eight terminations of pregnancy (34.8\%), two intrauterine deaths $(8.7 \%)$, five postnatal deaths (before or after surgery) $(21.7 \%)$; the remaining eight neonates $(34.8 \%$ ) are alive and thriving after surgery (six) or awaiting surgery (two).

Conclusions: CAT can be reliably diagnosed and characterised in prenatal life, although differentiation from PAVSD may be challenging. The association with chromosomal anomalies is consistent (8.7\%), but there is a higher risk of $22 q 11$ microdeletion (31.6\%), in agreement with postnatal studies. The relatively poor survival rate $(34.8 \%)$ reflects the high rate of terminations and the unfavourable cardiac anatomy in some cases.
\end{abstract}

extracardiac and chromosomal anomalies, and to evaluate the fetal-neonatal outcome in a multicentre fetal series of 23 cases of CAT.

\section{METHODS}

We report an observational study undertaken at three referral centres for prenatal diagnosis of congenital anomalies, evaluating 23 cases of CAT observed in the period 1993 to 2002.

The following variables were retrieved from the database and evaluated: indication for referral, gestational age at diagnosis, anatomical variant of CAT, truncal valve features, presence of extracardiac and chromosomal anomalies, presence of fetal growth restriction, and pregnancy and fetalneonatal outcome.

All cases underwent fetal echocardiography and detailed anatomical scan. Karyotyping was available in 22 of the 23 cases. Fetal echocardiography was done with ultrasound systems provided with pulsed, continuous, and colour Doppler (Prosound 5000 Aloka, Tokyo, Japan; Hewlett Packard Sonos 550, Andover, Massachusetts, USA; Toshiba Powervision 6000, Tokyo, Japan).

In the last 15 of the 23 cases the thymus was evaluated on the three vessel view, as described by Chaoui and colleagues. ${ }^{6}$ As reported postnatally, thymic hypoplasia was suspected reports, most cases being described along with other Our aim in this study was to assess the accuracy of the prenatal diagnosis, to investigate the association with 
when the great vessels were located close to the sternum and not centrally in the upper mediastinum, and was confirmed by evaluation of thymus size. ${ }^{78}$

In 19 of the 23 cases fluorescent in situ hybridisation (FISH) for the Di George syndrome critical region (22q11) was undertaken; in all these cases, slides were analysed by FISH using the following probes: N25 (D22S75 within 22q11.2)/WI-941 (within 22q13) from ONCOR (Gaithersburg, Maryland, USA), and TUPLE 1 (within22q11.2)/ARSA (arysulfatase A within 22q13.3l $\rightarrow$ qter) from Vysis (Downers Grove, Illinois, USA). If a chromosome 22 deletion was detected in the fetus, permission to carry out FISH analysis on the parents was requested to determine the inheritance pattern.

Necropsy reports and postnatal surgical/medical files were available for confirmation of the prenatal diagnosis in all cases.

\section{RESULTS}

Among the total of 1970 fetal heart defects detected in the referral centres during the observation period, CAT was diagnosed in 23 fetuses (1.16\%). The data are summarised in tables 1 and 2. Reasons for referral were: suspected heart malformation in 12 cases $(52.1 \%)$, extracardiac anomaly in five cases $(21.7 \%)$, and a positive family history in three cases (13.1\%). In the remaining three cases, the anomaly was detected during routine obstetric ultrasound examinations done by the authors themselves.

Mean gestational age at the time of diagnosis was 25 weeks (range 17-36 weeks), 12 cases having been diagnosed before 24 weeks' gestation. CAT was diagnosed prenatally in 24
Table 2 Common arterial trunk $(n=23)$ : associated clinical findings detectable at prenatal ultrasound examination in relation to the presence and type of chromosomal anomalies

\begin{tabular}{|c|c|c|c|}
\hline & $\begin{array}{l}\text { Cases with } 22 q 11 \\
\text { microdeletion }\end{array}$ & $\begin{array}{l}\text { Cases with } \\
\text { aneuploidy }\end{array}$ & $\begin{array}{l}\text { Other } \\
\text { cases }\end{array}$ \\
\hline $\begin{array}{l}\text { Additional aortic arch } \\
\text { anomalies }\end{array}$ & $4 / 6^{*}$ & $0 / 2$ & $2 / 15 \dagger$ \\
\hline Fetal growth restriction & $2 / 6$ & $2 / 2$ & $1 / 15$ \\
\hline Thymus hypo- or aplasia & $5 / 5$ & & $1 / 9 \ddagger$ \\
\hline Extracardiac anomalies & $4 / 6$ & $2 / 2$ & $4 / 15$ \\
\hline
\end{tabular}

*In one case aberrant right subclavian artery was not diagnosed at prenatal ultrasound examination.

†Both cases not recognised at prenatal ultrasound examination. fln one case thymus could not be assessed (case 14); one case (20) resulted false positive at necropsy.

cases, and confirmed in 23, the remaining neonate having PAVSD, which was incorrectly diagnosed in utero as CAT. The characterisation of CAT types made at fetal echocardiography was confirmed in all cases at necropsy or at postnatal echocardiography or surgery. In one case it was not possible to make a prenatal diagnosis of the type of CAT because the pulmonary arteries had a different origin from that of types I, II, and III (case 13). In this case only one pulmonary artery arose from the trunk, while the other was apparently absent but was then identified at necropsy within the hilum of the lung (discontinuous pulmonary artery).

Although the truncal valve is commonly connected to both ventricles, it may sometimes straddle one ventricle preferen-

Table 1 Study subjects with common arterial trunk

\begin{tabular}{|c|c|c|c|c|c|c|c|c|}
\hline Case & $\begin{array}{l}\text { Gestational } \\
\text { age (weeks) }\end{array}$ & Referral diagnosis & Type & $\begin{array}{l}\text { Associated heart } \\
\text { anomalies }\end{array}$ & Extracardiac anomalies & $\begin{array}{l}\text { Cytogenetic/FISH } \\
\text { aberrations }\end{array}$ & TV regurgitation & TV stenosis \\
\hline 1 & 22 & $\begin{array}{l}\text { Extracardiac } \\
\text { anomalies }\end{array}$ & 1 & & $\begin{array}{l}\text { Holoprosencephaly, } \\
\text { dysplastic kidneys }\end{array}$ & Trisomy 13 & Absent & Absent \\
\hline 2 & 17 & $\begin{array}{l}\text { Extracardiac } \\
\text { anomalies }\end{array}$ & $\|$ & & $\begin{array}{l}\text { Holoprosencephaly, } \\
\text { dysplastic kidneys }\end{array}$ & ND & Absent & Absent \\
\hline 3 & 23 & $\begin{array}{l}\text { Extracardiac } \\
\text { anomalies }\end{array}$ & III & & $\begin{array}{l}\text { Cleft lip and palate, corpus } \\
\text { callosum agenesis + NIHF }\end{array}$ & Trisomy 22 & Present & Present \\
\hline 4 & 23 & Abnormal heart & 1 & & $\begin{array}{l}\text { Ectrodactyly imperforate } \\
\text { anus }\end{array}$ & & Absent & Absent \\
\hline 5 & 21 & $\begin{array}{l}\text { Positive family } \\
\text { history }\end{array}$ & 1 & IAA+ASD & & & Absent & Absent \\
\hline 6 & 26 & Abnormal heart & I & $\begin{array}{l}\text { TA, dextrocardia, } \\
\text { TAPVC }\end{array}$ & & & Present & Present \\
\hline 7 & 36 & Routine & 1 & & & & Absent & Absent \\
\hline 8 & 23 & $\begin{array}{l}\text { Positive family } \\
\text { history }\end{array}$ & 1 & & & & Absent & Absent \\
\hline 9 & 29 & Abnormal heart & I & & & & Absent & Present \\
\hline 10 & 20 & Routine & i & RAA & & $22 q 11$ microdeletion & Absent & Absent \\
\hline 11 & 28 & Abnormal heart & $\|$ & IAA, ARSA & Mild hydronephrosis & $22 q 11$ microdeletion & Absent & Absent \\
\hline 12 & 34 & Abnormal heart & 1 & & Unilateral renal agenesis & $22 q 11$ microdeletion & Absent & Absent \\
\hline 13 & 35 & Abnormal heart & ND & $\begin{array}{l}\text { RAA, discontinuous } \\
\text { PA }\end{array}$ & Oesophageal atresia & $22 q 11$ microdeletion & Absent & Absent \\
\hline 14 & 19 & Abnormal heart & I & Mitral atresia & $\begin{array}{l}\text { Mild cerebral } \\
\text { ventriculomegaly }\end{array}$ & & Absent & Absent \\
\hline 15 & 23 & Abnormal heart & 1 & & & & Present & Present \\
\hline 16 & 28 & $\begin{array}{l}\text { Extracardiac } \\
\text { anomalies }\end{array}$ & $\|$ & RAA & $\begin{array}{l}\text { Mild cerebral } \\
\text { ventriculomegaly }\end{array}$ & $22 q 11$ microdeletion & Absent & Absent \\
\hline 17 & 21 & $\begin{array}{l}\text { Positive family } \\
\text { history }\end{array}$ & $\|$ & & & & Absent & Absent \\
\hline 18 & 21 & Routine & I & ARSA & & & Absent & Absent \\
\hline 19 & 21 & Abnormal heart & $\|$ & & & $22 q 11$ microdeletion & Absent & Absent \\
\hline 20 & 28 & $\begin{array}{l}\text { Extracardiac } \\
\text { anomalies }\end{array}$ & III & & Duodenal atresia & & Present & Present \\
\hline 21 & 28 & Abnormal heart & $\|$ & & & & Absent & Absent \\
\hline 22 & 27 & Abnormal heart & I & & & & Absent & Absent \\
\hline 23 & 26 & Abnormal heart & 1 & & & & Absent & Absent \\
\hline
\end{tabular}


tially, as in three of our cases, especially if there is predominance of one of the ventricles. In all three cases the truncal valve straddled the right ventricle. When there is atrioventricular valve atresia, a common arterial trunk may arise just from one ventricle, as in two of our cases (cases 6 and 14). In the case of tricuspid atresia, the single great vessel arose from what appeared to be a single left ventricle and partially overrode the hypoplastic right ventricle. In the case of mitral atresia and hypoplastic left ventricle, the CAT arose only from the right ventricle. In both cases the VSD was restrictive.

Truncal valve regurgitation was present in four patients (cases 3, 6, 15, and 20). In two cases the regurgitation was confirmed at postnatal echocardiography (cases 6 and 15); the third case, a fetus with cardiomegaly, died in utero (case 20 ), and in the remaining case the parents chose to have the pregnancy terminated (case 3). In two other cases, a mild truncal valve regurgitation was detected at postnatal echocardiography.

Truncal valve stenosis, defined as a Doppler velocity of $>1.9 \mathrm{~m} / \mathrm{s}$ across the valve, was present in five cases $(3,6,9$, 15 , and 20). In another case, this anomaly was suspected at prenatal echocardiography but not confirmed at postnatal examination (case 12).

In six of 23 fetuses with CAT, other cardiovascular anomalies were identified at fetal echocardiography (table 1): right aortic arch (cases 10, 13, and 16); interruption of the aortic arch (case 11); tricuspid atresia, dextrocardia, and total anomalous venous pulmonary connection (case 6); and mitral atresia and VSD (case 14). In two of these fetuses already diagnosed with second lesions, additional cardiac anomalies were overlooked prenatally: aberrant right subclavian artery in case 11 and a discontinuous pulmonary artery in case 13. In two other fetuses, a case of interruption of the aortic arch and atrial septal defect (case 5) and a case of aberrant right subclavian artery (case 18) went unrecognised.

Extracardiac anomalies were present in 10 cases (cases 1 , $2,3,4,11,12,13,14,16$, and 20) (table 1); in case 4, they were missed at prenatal ultrasound. In two of these fetuses, chromosomal anomalies were also present (cases 1 and 3). FISH analysis was done in 19 fetuses; in six $(31.6 \%)$, the 22q11 microdeletion was detected (cases 10, 11, 12, 13, 16, and 19), and in four, extracardiac anomalies had already been diagnosed. At the time of the first four diagnoses, FISH analysis was not available at two of the centres.

As Di George syndrome, which encompasses most cases associated with microdeletion, is commonly associated with thymic hypoplasia or aplasia, we tried to ascertain whether the presence of thymic developmental defects might be detected by prenatal ultrasound examination, using a high frequency transducer. This analysis was done in 15 fetuses of our series (five with microdeletion). It was found that the thymus could be identified as a structure in front of the great vessels in the three vessel/tracheal view. In one case only, the thymus could not be assessed because of both maternal obesity and the early gestational age (case 14). However, prenatal examination identified all five cases of absent or hypoplastic thymus, while a false positive result was obtained in one case. This was a case of CAT with severe truncal valve insufficiency and cardiomegaly, in whom visualisation of the thymus could have been hampered by compression by surrounding structures and consequent displacement of the fetal thymus (case 20).

In eight of 12 cases (cases 1, 2, 3, 4, 10, 14, 18, and 19) detected before 24 weeks' gestational age, the parents chose to terminate the pregnancy (table 1); of the remaining 15 , two died in utero, one being affected by severe growth restriction and the other by lethal heart failure from massive truncal valve regurgitation and volume overload (cases 16 and 20). Of the 13 neonates, three died before surgery and had other cardiac or extracardiac anomalies (cases 6,11 , and 13). Eight underwent cardiac surgery in the first 43 days (median age 20 days): two had a palliative operation and six had corrective procedures. Death occurred after surgery in two cases (cases 5 and 15): both had unfavourable anatomy (additional major cardiac anomalies in case 5 and severe truncal valve regurgitation in case 15). Of the six infants who survived after corrective or palliative surgery (cases 8, 9, 12, 17, 21, and 22) only one had extracardiac anomalies (case 12). None had associated cardiac anomalies, truncal valve regurgitation, or fetal growth retardation. These six infants are currently alive and thriving at a median follow up of 10 months. The remaining two neonates are being followed and are awaiting surgery (cases 7 and 23) (fig 1).

In three neonates (cases 11, 12, and 13) with CAT and 22qll microdeletion, characteristic features of Di George syndrome were present: hypocalcaemia, T cell abnormalities, and overt thymic hypoplasia. Two of these infants died before surgery (cases 11 and 13), one of whom also featured low birth weight.

All the neonates born with CAT had been identified and correctly diagnosed in utero.

\section{DISCUSSION}

In the last decade, the accuracy of prenatal diagnosis of congenital heart disease and its counselling has greatly improved, thanks to effective collaboration between geneticists, paediatric cardiologists, and obstetricians-for congenital heart disease is often associated with extracardiac anomalies and genetic syndromes. A detailed ultrasound evaluation of fetal anatomy and a precise description of cardiac malformations at fetal echocardiography have enhanced genetic correlations and have led to an improved understanding of the prognosis for affected fetuses. ${ }^{9-12}$ Prenatal diagnosis of CAT by fetal echocardiography has already been reported. ${ }^{2-5}$ Our figures regarding mean and median gestational age at diagnosis do not differ significantly from those reported by Duke and colleagues ( 25 and 23 weeks $v 24$ and 22.5 weeks, respectively). ${ }^{5}$ The relatively advanced gestational age at diagnosis is probably related to the fact that in CAT_as in all malformations of the outflow tracts-the four chamber view of the fetal heart, which constitutes the keystone of prenatal screening, may be unremarkable. ${ }^{45}$

Prenatal ultrasound may also be used to identify CAT types and variants with a good degree of accuracy, as shown in our study, which is the largest series of fetuses with CAT reported to date. In most cases, the diagnosis of CAT was made at the first scan. Only one case of PAVSD was incorrectly diagnosed as CAT (the first such diagnosis at one of the centres), while in two other cases it was possible to differentiate PAVSD from CAT. We believe that this differential diagnosis represents the most challenging task to be faced when diagnosing CAT in the fetus: CAT types II and III and PAVSD share the reduced dimensions of the pulmonary branches and the prevalence of the aortic vessel. When doubts arise, the following anatomical details should be sought to make the final diagnosis: the aortic/truncal valve, the atretic pulmonary valve, and the direction of flow within the arterial duct. The semilunar valve is often abnormal (from two to five cusps) and typically stenotic or insufficient in CAT, whereas it is frequently unremarkable or only mildly abnormal in PAVSD. The atretic pulmonary valve is difficult to detect in PAVSD but if demonstrated (in those infrequent cases in which the pulmonary trunk is not extremely hypoplastic), CAT can be excluded. Finally, accurate colour Doppler mapping of the great vessels may help to detect reversed 


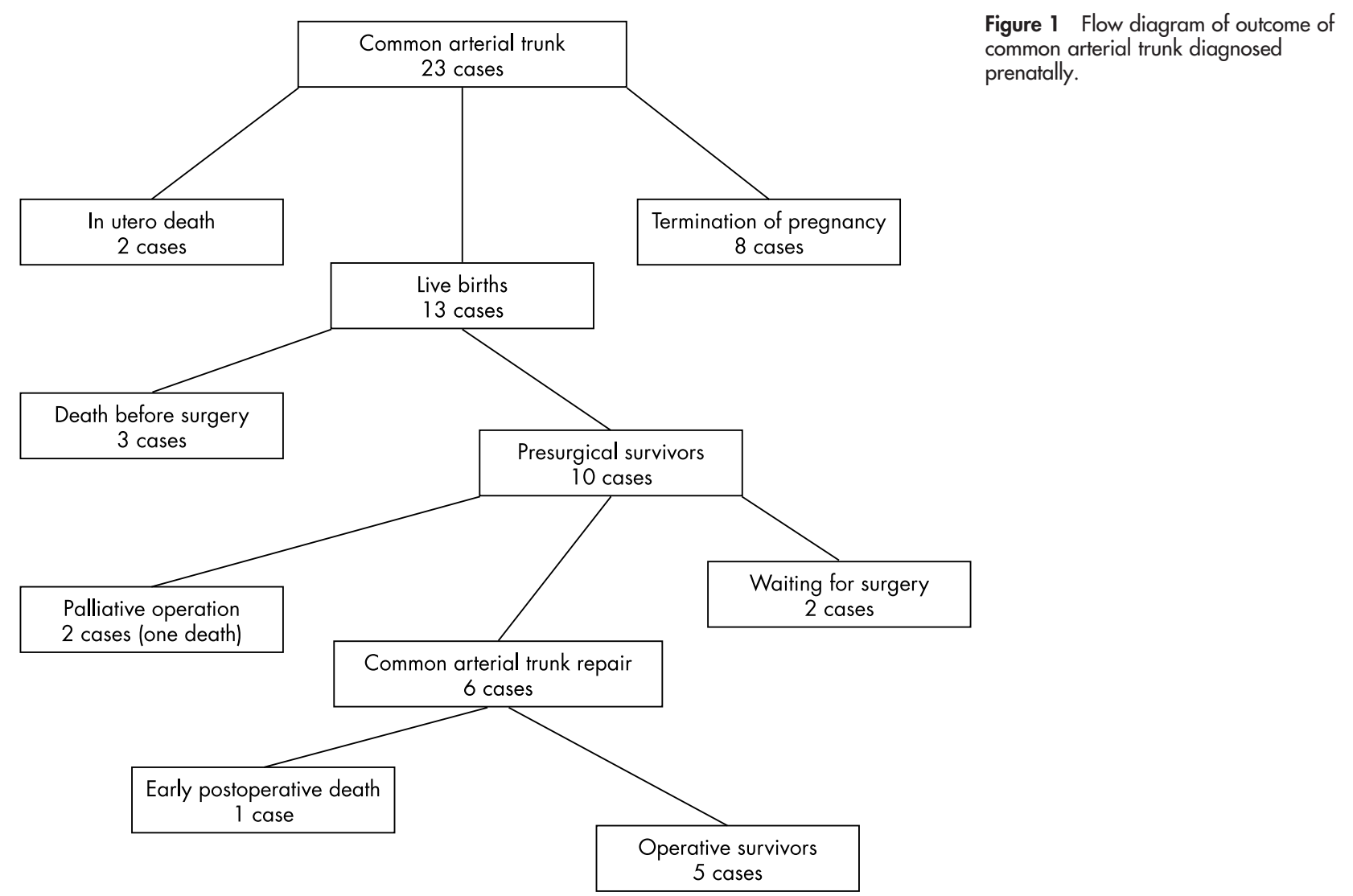

flow in the arterial duct and main pulmonary artery as well as aorto-pulmonary collaterals in PAVSD, or the branching point of the pulmonary arteries in the truncal vessel in CAT types II-III.

When CAT is diagnosed in a fetus, care should be taken to identify possible additional heart and great vessels anomalies, which are far from infrequent (34.8\% in this series). In particular, the operator should be alerted to the possible presence of arch anomalies, for these may increase the risk of 22qll microdeletion (right aortic arch, interruption of the aortic arch), which will worsen the long term prognosis in the case of interrupted aortic arch. The diagnosis of these conditions is, admittedly, not always straightforward, and one such case (interruption of the aortic arch) went unrecognised in the present case series. In these cases, the transverse view of the upper mediastinum is very helpful, allowing both thymus and arch anomalies to be detected; in our opinion it is essential to obtain this view not only while scanning fetuses with CAT but with all malformations of the outflow tracts.

As previously demonstrated, CAT is frequently associated with genetic anomalies. ${ }^{13}{ }^{14}$ Our study confirms that fetuses with CAT often feature the 22q11 microdeletion (six of 19 cases). In these cases, other cardiac anomalies-especially arch or vessel anomalies (that is, right aortic arch, aberrant right subclavian artery)—are commonly present as well; in fact, arch anomalies were present in four of our six cases with microdeletion and in only two of 13 cases without microdeletion. Thus the diagnosis of prenatally detectable arch anomalies (right aortic arch, interruption of the aortic arch) in fetuses diagnosed with CAT should be regarded as a strong marker of 22q11 microdeletion. Fetal growth retardation was also a marker of $22 \mathrm{ql} 1$ microdeletion, at least in our series, although less specific than arch anomalies, for it was also present in the two cases of autosomal trisomies (table 1).
As prenatal thymus ultrasound has been shown to be feasible only in the last two years, there are few data on the sonographic appearance and size of the thymus in the fetus or on the clinical implications of detecting an aplasic/ hypoplasic thymus in fetuses with $22 \mathrm{q} 11$ microdeletion. ${ }^{6-8}$ Our data suggest that prenatal examination of the thymus has high sensitivity for detecting 22q11 microdeletions associated with CAT, though some caution is required, given the possible technical limitations of such an approachespecially in cases of maternal obesity and early gestational age, or abnormal intra-thoracic anatomy (for example, cardiomegaly or diaphragmatic hernia). Ultrasound investigation of the fetal thymus is especially difficult in cases of altered intrathoracic anatomy, as shown by our false positive case, because of possible compression and displacement of the gland by the adjacent viscera. Moreover, it must be emphasised that most, but definitely not all, cases of $22 \mathrm{ql} 1$ microdeletion are associated with thymic defects. ${ }^{15}{ }^{16} \mathrm{In}$ fact, only a subset of the patients with the most common genomic disorder on 22q11, the VeloCardioFacial/DiGeorge syndrome, show a hypoplasic or absent thymus and hypocalcaemia. ${ }^{17}$

The prenatal finding of $22 \mathrm{q} 11$ deletion enables clinicians to provide the couple with full informative counselling: they should receive information about the $22 \mathrm{q} 11$ deletion phenotype findings, recurrence risk, and disease variability, as well as prognosis. In two of our cases detected before the 24th gestational week, the risk of mental retardation associated with the respective risk of cardiac surgery for each type of heart defect led to the parents choosing to terminate the pregnancy.

Extracardiac structural anomalies were present in 10 of 23 cases of CAT, most often in the context of specific syndromes (six of our 10 cases), and represented the indication for referral in five cases $(21.7 \%)$. Recent embryological reports provide some explanations for these data; in fact, we now 
know that at the early stage of the straight tube, the primordial heart consists only of the right ventricle (cranial) and the left ventricle (caudal). Atrial and conotruncal components appear and subsequently become incorporated with the ventricles. For normal formation of the definitive heart, many extracardiac structures are needed; therefore, it is not surprising that in the presence of major extracardiac anomalies and genetic syndromes there is a significant incidence of cardiac anomalies. ${ }^{18} 19$

The truncal valve may show varying degrees of dysplasia and may be stenotic or regurgitant or both. ${ }^{50}$ In this series, it was regurgitant in four and stenotic in five. In two other cases, mild truncal valve regurgitation was detected at postnatal echocardiography. In three of four cases of severe truncal valve regurgitation there were four valve cusps. The degree of valve stenosis was significantly correlated with the degree of valve regurgitation. In the case of isolated valve stenosis there were two valve cusps. In the presence of truncal valve regurgitation, one fetus with cardiomegaly died in utero (case 20), one neonate died before surgery (case 6), and one died after surgery (case 15), while in the remaining case the parents chose to terminate the pregnancy (case 3 ). Thus truncal valve regurgitation seems to represent a bad prognostic sign, as shown also in postnatal studies, although the numbers are too small to be statistically useful. ${ }^{20}$

\section{Conclusions}

We have confirmed that CAT can be diagnosed reliably prenatally, as shown by other investigators, ${ }^{5}$ although in some instances its differential diagnosis from PAVSD may cause some difficulty. In addition, we have shown that, when diagnosed in the fetus, CAT is commonly associated with extracardiac anomalies, often in the context of specific syndromes - the most common association being with the 22 q11 microdeletion $(31.6 \%)$. Our data also seem to show a significant association between CAT and fetal growth retardation, especially in cases with genetic anomalies, though the significance of this finding is limited by the small number of cases. The relatively poor survival rate mainly reflects the high rate of terminations and the unfavourable cardiac anatomy in some cases (for example, interruption of the aortic arch or truncal valve regurgitation).

\section{ACKNOWLEDGEMENTS}

We thank Mrs Paola Fiorente and Mr Caterina Nanna for technical help.

\section{Authors' affiliations}

P Volpe, Department of Obstetrics and Gynaecology, Hospital "Di Venere-Giovanni XXIII", Bari, Italy
D Paladini, M Vassallo, P Martinelli, Fetal Cardiology Unit, Department of Gynaecology and Obstetrics, University Federico II of Naples, Italy M Marasini, Department of Paediatric Cardiology, Giannina Gaslini Institute, Genova, Italy

A L Buonadonna, M Gentile, Department of Medical Genetics, IRCCS "Saverio de Bellis", Castellana Grotte- Bari, Italy

M G Russo, Division of Paediatric Cardiology, 2nd University of Naples, Monaldi Hospital, Naples, Italy

G Caruso, A Marzullo, Department of Pathological Anatomy and Genetics, University of Bari, Bari, Italy

\section{REFERENCES}

1 Collett RW, Edwards JE. Persistent truncus arteriosus: a classification according to anatomic types. Surg Clin North Am 1949;29:1245-70.

2 Allan LD, Sharland GK, Milburn A, et al. Prospective diagnosis of 1006 consecutive cases of congenital heart disease in the fetus. J Am Coll Cardiol 1994:23:1452-8.

3 Marasini M, Cordone M, Zampatti C, et al. Prenatal ultrasonic detection of truncus arteriosus with interrupted aortic arch and truncal valve regurgitation. Eur Heart J 1987;8:921-4.

4 Paladini D, Rustico MA, Todros T, et al. Conotruncal anomalies in prenatal life. Ultrasound Obstet Gynecol 1996;8:241-6.

5 Duke C, Sharland GK, Jones AMR, et al. Echocardiographic features and outcome of truncus arteriosus diagnosed during fetal life. Am J Cardiol 2001;88:1379-84.

6 Chaoui R, Kalache KD, Heling KS, et al. Absent or hypoplastic thymus on ultrasound: a marker for deletion 22q11.2 in fetal cardiac defects. Ultrasound Obstet Gynecol 2002;20:546-52.

7 Yeager SB, Sanders SP. Echocardiographic identification of thymic tissue in neonates with congenital heart disease. Am Heart J 1995;129:837-9.

8 Zalel Y, Gamzu R, Mashiach S, et al. The development of the fetal thymus: an in utero sonographic evaluation. Prenat Diagn 2002;22:114-17.

9 Allan LD. Fetal echocardiography. In: Moller JH, Hoffman JIE, eds. Pediatric cardiovascular medicine. Philadelphia: Churchill Livingstone, 2000:187-202.

10 Boudjemline Y, Fermont L, Le Bidois J, et al. Prevalence of 22q1 1 deletion in fetuses with conotruncal cardiac defects: a 6 -year prospective study. J Pediatr $2001 ; 138: 520-4$.

11 Gardiner HM. Fetal echocardiography: 20 years of progress. Heart 2001;86(suppl 2):I112-22

12 Boudjemline Y, Fermont L, Le Bidois J, et al. Can we predict $22 q 11$ status of fetuses with tetralogy of Fallot? Prenat Diagn 2002;22:231-4.

13 Goldmuntz E, Clark BJ, Mitchell LE, et al. Frequency of $22 q 11$ deletions in patients with conotruncal defects. J Am Coll Cardiol 1998;32:492-8.

14 Marino B, Digilio MC, Toscano A, et al. Anatomic patterns of conotruncal defects associated with deletion 22q11. Genet Med 2001;3:45-8.

15 Scambler PJ. The $22 q 11$ deletion syndromes. Hum Mol Genet 2000;9:2421-6.

16 Volpe $\mathbf{P}$, Gentile M, Marasini M. Interrupted aortic arch type A with 22q11 deletion: prenatal detection of an unusual association. Prenat Diagn 2002;22:371-4.

17 Burn J, Goodship J. Congenital heart disease. In: Rimoin DL, Connor JM, Pyeritz RE, eds. Principles and practice of medical genetics, 4th ed. London: Churchill Livingstone, 2002:1248-53.

18 Kirby ML. Role of extracardiac factors in heart development. Experimentia 1988;44:944-50.

19 Clark EB, Nakazawa M, Takao A. Etiology and morphogenesis of congenital heart disease: twenty years of progress in genetics and developmental biology. New York: Futura Publishing Co, 2000

20 Williams JM, de Leeuw M, Black MD, et al. Factors associated with outcomes of persistent truncus arteriosus. J Am Coll Cardiol 1999;34:545-53.

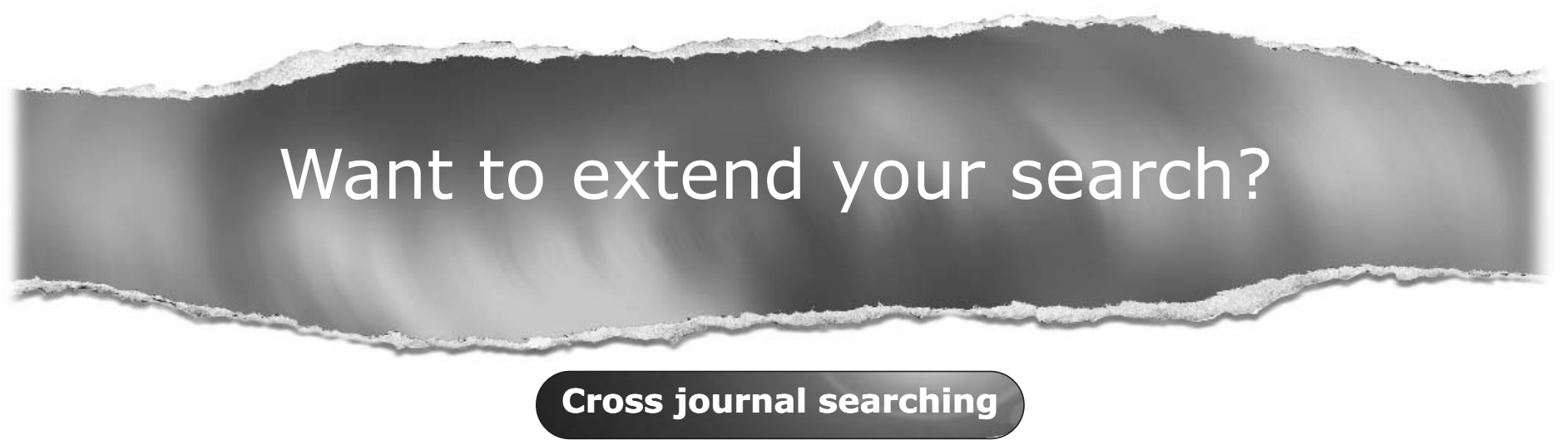

Can't find what you're looking for in Heart? Extend your search across $340+$ journals.

Search restriction options include specific subject areas (eg. clinical medicine, basic research), select specific journals or search all available titles. 